\section{Trabalhador "compatível", fratura exposta no processo de produção da indústria automobilística: intensificação do trabalho e saúde em questão}

\section{Trabajador "compatible", una brecha expuesta en el proceso de producción de la industria automovilística: intensificación del trabajo y salud en tela de juicio}

José Augusto Pina 1

Eduardo Navarro Stotz 1

José Marçal Jackson Filho 2

\section{Resumo}

O atual processo de intensificação do trabalho se insere no contexto das transformações produtivas, no Brasil, a partir dos anos 1990, acarretando mudanças na produção social do desgaste operário e do perfil epidemiológico dos trabalhadores. Incapacidade para o trabalho por acidente e doença é um importante indicador do desgaste operário, sendo de interesse da área da saúde. $O$ estudo objetiva analisar o processo de intensificação do trabalho e saúde da perspectiva do processo saúde-doença a partir da percepção dos trabalhadores de uma montadora automobilística da Região do ABC, em São Paulo, quando indagados acerca dos obstáculos ao retorno ao trabalho daqueles com restrição laboral por acidente ou doenças, comumente denominados de "compativel”. Realizamos seis visitas à fabrica e vinte entrevistas com operários da produção. Os dados foram coletados entre março de 2010 e novembro de 2014. Os resultados revelam, na figura social do "compativel", uma fratura exposta pelo processo de produção, expressa nas práticas de intensificação do trabalho, caracterizada pelo ritmo intenso, adensamento do trabalho, prolongamento da jornada e gestão por estresse; ao mesmo tempo, apontam para a tendência de exclusão do trabalhador "compatível" da empresa. A pesquisa contribui para avançar na busca do conhecimento acerca da intensificação do trabalho e saúde, esperamos ter trazido subsídios para novas investigações na perspectiva da determinação do processo saúde-doença, com a incorporação da experiência dos trabalhadores.

Carga de Trabalho; Previdência Social; Saúde do Trabalhador

\author{
Correspondência \\ J. A. Pina \\ Centro de Estudos da Saúde do Trabalhador e Ecologia \\ Humana, Escola Nacional de Saúde Pública Sergio Arouca, \\ Fundação Oswaldo Cruz. \\ Rua Leopoldo Bulhões 1480, Rio de Janeiro, RJ 21041-210, \\ Brasil. \\ augusto@ensp.fiocruz.br \\ 1 Escola Nacional de Saúde Pública Sergio Arouca, Fundação
Oswaldo Cruz, Rio de Janeiro, Brasil.
2 Fundação Jorge Duprat Figueiredo de Segurança e Medicina
do Trabalho, Curitiba, Brasil.
}




\section{Introdução}

Na sociedade contemporânea, a intensificação do trabalho influencia, cada vez mais, a saúde dos trabalhadores por meio do aumento das exigências mentais, emocionais e físicas. Trata-se de tendência global que ocorre em diversos setores econômicos com nuances diversas 1,2,3. No Brasil, apenas recentemente, a intensificação do trabalho e seus efeitos à saúde dos trabalhadores tornaram-se preocupação central de pesquisa 4,5 .

Intensificação do trabalho é uma dimensão social particular da análise dos processos de trabalho; trata-se de processo contraditório e histórico, pelo qual se produz e se obtém uma maior quantidade de trabalho, no mesmo intervalo de tempo, no curso do desenvolvimento e transformação da produção ${ }^{6}$. Nas últimas décadas, pode ser considerada como resultado da reestruturação produtiva, que, ao implantar mudanças tecnológicas, gerenciais e organizacionais a fim de maior produtividade, implicou na degradação da qualidade do trabalho e provocou efeitos à saúde $7,8,9,10$.

A reestruturação produtiva das montadoras da indústria automobilística no Brasil, a partir dos anos 1990, provocou alterações no processo de desgaste operário e no perfil de morbidade dos trabalhadores: de um lado, a manutenção de agravos à saúde como acidentes de trabalho típicos e, em menor magnitude, de perda auditiva induzida por ruído (PAIR) e intoxicações; de outro, a emergência e expansão de problemas de saúde como as doenças crônicas não transmissíveis (DCNT), como lesão por esforço repetitivo (LER), doenças cardiovasculares e do aparelho circulatório, além de problemas psíquicos 11. Esse perfil das doenças crônicas na população trabalhadora é similar ao da população geral, porém tende a ocorrer mais precocemente entre os trabalhadores quando comparados com a população geral 8.

Incapacidade para o trabalho em decorrência de acidentes e doenças é um importante indicador do desgaste do trabalhador, sendo de interesse da área da saúde, pois, ao mesmo tempo em que resulta de processos recentes de intensificação, possibilita problematizar o processo de produção nas empresas e nos setores de atividade econômica.

Ou seja, a incapacidade para o trabalho, entendida como um sinal, individual e coletivo, ora reprimido, ignorado, distorcido ou, ainda, parcialmente reconhecido 12 na e pela sociedade, na medida em que é analisada a partir do processo de intensificação do trabalho, permite conhecer, de modo mais amplo e aprofundado, os problemas de saúde do coletivo de trabalhadores. Além do reconhecimento do adoecimento relacionado ao trabalho, o retorno ao trabalho, sobretudo dos trabalhadores com incapacidade permanente parcial, também é marcado por conflitos, uma vez que apresentam redução definitiva da capacidade laboral.

Este artigo tem por objetivo analisar o processo de intensificação do trabalho, da perspectiva do processo saúde-doença, a partir da percepção dos trabalhadores de uma montadora automobilística da Região do ABC, Estado de São Paulo, Brasil. Nessa empresa, a intensificação pode ser caracterizada pela diminuição, entre 1991 a 2011, do número de empregados de 20.625 para 12.294, com aumento da produção anual de veículos por trabalhador que passou de 2,0, em 1991, 3,8, em 1999, 4,8, em 2005, e atingiu 6,5, em 2011. Como os ganhos de produtividade foram obtidos, conforme veremos neste estudo, simultaneamente ao aumento dos danos à saúde dos trabalhadores, estamos diante de um processo marcado pela intensificação do trabalho ${ }^{9}$. Ao trazer para reflexão o modo como os trabalhadores percebem os obstáculos ao retorno e a permanência do trabalhador com incapacidade permanente parcial na empresa, nosso propósito é examinar as características da intensificação do trabalho como um modo de produção social do desgaste laboral manifesto em doenças, agravos, incapacidades e múltiplos problemas de saúde.

\section{Metodologia}

O quadro teórico-conceitual deste estudo se estrutura no âmbito da determinação histórica e social do processo saúde-doença, mais especificamente nas relações entre produção e saúde 13 .

Estudar a intensificação do trabalho e saúde na produção visa também olhar para as experiências no local de trabalho que delineiam possibilidades e limites de seu enfrentamento com a participação 
dos trabalhadores. Trata-se de uma importante questão teórico-metodológica que orienta os procedimentos adotados nesta pesquisa em termos de coleta, análise e interpretação dos dados.

$\mathrm{O}$ universo da pesquisa compreendeu os operários da produção direta na montadora. Os dados foram coletados entre março de 2010 e novembro de 2014. Adotaram-se os seguintes procedimentos metodológicos: trabalho de campo e a entrevista semidiretiva e individual. O trabalho de campo incluiu seis visitas à fábrica, todas guiadas pelos diretores do Comitê Sindical de Empresa (CSE) e da Comissão Interna de Prevenção de Acidentes (CIPA). As visitas possibilitaram a coleta de informações acerca da organização da produção, dos acordos coletivos de trabalho e dados estatísticos do ambulatório médico da empresa.

A entrevista aprofundou a incursão na realidade da montadora. Foram realizadas vinte entrevistas: cinco com representantes na CIPA/CSE e 15 com operários da linha de montagem e usinagem. Desses, foram incluídos cinco com incapacidade permanente parcial.

O diálogo entre objeto de estudo e os dados coletados guiaram, apoiados na perspectiva proposta por Bourdieu 14, a análise e a interpretação dos dados. A interpretação dos dados resulta do cruzamento entre as estruturas de pensamento dos entrevistados e seu cotejamento com o referencial teóricoconceitual da saúde do trabalhador. Na esteira de Huw Beynon, a redação deste artigo tomou, como ponto de partida, a construção das frases dos trabalhadores, sobretudo para realçar a reflexão operária acerca das características da intensificação do trabalho e saúde 15.

Este estudo foi aprovado pelo Comitê de Ética em Pesquisa da Escola Nacional de Saúde Pública Sergio Arouca, Fundação Oswaldo Cruz, conforme parecer no 46/2011.

\section{Resultados e discussão}

\section{Trabalhador compatível e perfil dos danos à saúde de etiologia relacionada ao trabalho}

Entre os metalúrgicos da Região do ABC, o termo "compatível" designa o trabalhador com incapacidade permanente parcial que, após tratamento e reabilitação profissional, apresenta restrição definitiva, originada por acidente ou doença, para o exercício de suas atividades, mas que preserva as condições para exercer outra atividade ou função "compatível" à sua capacidade laboral. De acordo com a existência ou não de nexo entre o trabalho e o dano à saúde, os compatíveis são agrupados em ocupacional e não ocupacional.

A convenção coletiva de trabalho nas montadoras do setor automobilístico da Região do ABC estabelece estabilidade no emprego até a aposentadoria para o trabalhador compatível ocupacional. Trata-se da principal conquista sindical de proteção contra a demissão do compatível.

$\mathrm{Na}$ empresa, o perfil dos danos à saúde que respondem pela redução da capacidade laboral do compatível ocupacional está constituído, basicamente: de um lado, por sequelas decorrentes de acidente de trabalho típico, especialmente as mutilações e amputações de dedos e mãos; de outro, a grande maioria, por lesões da coluna lombar e cervical e demais lesões e doenças osteomusculares.

Esse perfil é semelhante ao encontrado por estudos com trabalhadores da indústria 16 ou entre os atendidos pela reabilitação profissional da Previdência Social no Brasil 17.

Um índice desse perfil pode ser visto pela distribuição das lesões por parte do corpo afetada, pelos acidentes de trabalho típicos, geradores ou não de incapacidade temporária ou permanente, segundo dados da empresa, entre janeiro e agosto de 2009: dedos (115) e mãos (43) foram as partes mais afetadas, ambas, representaram $47,3 \%$ do total das lesões (334). Também pela ocorrência de fisioterapia por região do corpo para os dez setores com maior frequência de trabalhadores ao ambulatório da empresa: em 2005, das 605 ocorrências, 257 (42,5\%) foram para coluna lombar e cervical, e 228 (37,5\%), para ombro, punho, cotovelo e antebraço. Do mesmo modo, pelo crescimento do número de sessões de fisioterapia de 63.970, em 2000, para 73.363, em 2005, e, sobretudo, pelo aumento do tempo de permanência do trabalhador em tratamento fisioterápico no ambulatório da empresa: em 2000 , até cinco sessões, agrupavam 60\% dos atendidos, e, mais de cinco, 30\%. Em 2005, esses percentuais se inverteram, 30\% e 60\%, respectivamente. Em ambos os anos, ocorreram 10\% de abandono.

Esse quadro ganhou expressão no crescimento da incidência anual de trabalhadores compatíveis de 1999 a 2005 (Figura 1): o número de novos casos (ocupacional e não ocupacional) passou de 24, 
Figura 1

Novos casos de trabalhadores compatíveis, ocupacional e não ocupacional, na montadora, 1999-2005.

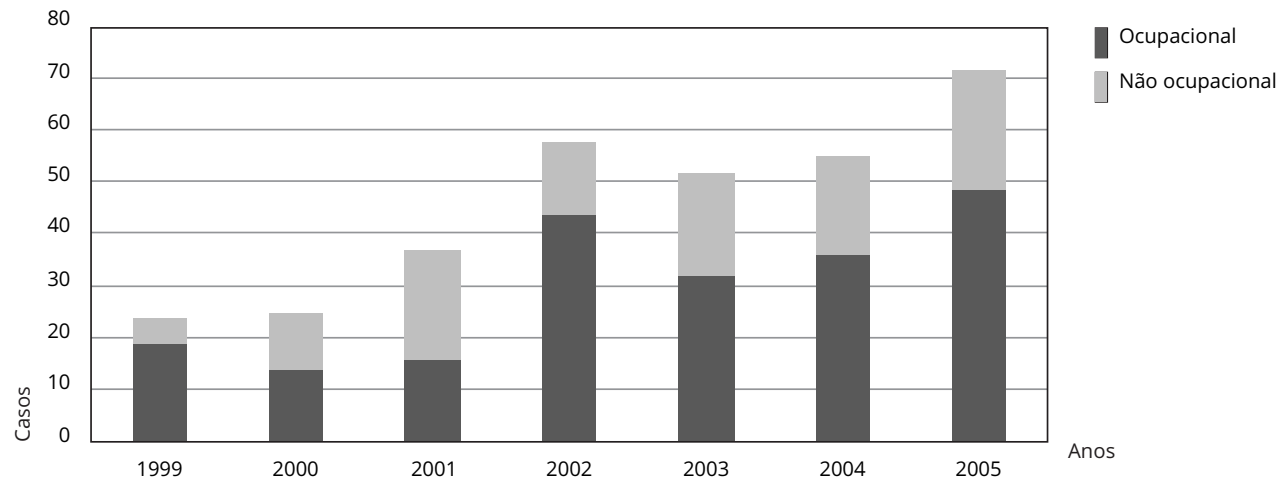

em 1999, para 72, em 2005, aumento de 200\%. O período totalizou 323 novos casos de compatíveis, desses, 210 ocupacionais e 113 não ocupacionais, respectivamente, 65\% e 35\%, ou seja, a maior participação absoluta e relativa dos casos ocupacionais no total de casos.

Entre os motivos para o aumento da incidência anual de compatíveis e a maior participação dos casos ocupacionais relativamente aos não ocupacionais, é possível apontar: primeiro, o maior conhecimento pelos trabalhadores e a dificuldade de ocultação das LER como doença relacionada ao trabalho, que, desde os anos 1990, responde pelo aumento da participação das doenças no total desses agravos relacionados ao trabalho registrados pela Previdência Social 17. Segundo, a iniciativa da CIPA/CSE, em 2003, em percorrer os setores da fábrica e cadastrar os operários com restrição médica definitiva, muitos casos ainda sem o reconhecimento legal pelo Instituto Nacional do Seguro Social (INSS) e pela empresa, ou seja, a realização de "busca ativa de casos" pela organização dos trabalhadores no local de trabalho.

Dos casos prevalentes, em janeiro de 2006, a empresa registrou o total de 1.045 trabalhadores compatíveis; desses, 408 (39\%) ocupacionais e 637 (61\%) não ocupacionais, participação diferente da evolução da incidência anual indicada na Figura 1.

O aumento do tempo de permanência do trabalhador em tratamento fisioterápico, de caráter sintomático e paliativo, e o crescimento dos novos casos de compatíveis são indicadores da continuidade e agravamento dos danos à saúde. Esse quadro também inclui o aumento da participação dos casos de PAIR no total de compatíveis: de 0,11\%, em 1999, para 0,33\%, em 2006, ou seja, o crescimento, nos anos 2000, de um agravo ocupacional, predominante do perfil epidemiológico dos trabalhadores antes da reestruturação produtiva da empresa, até então em queda.

A tendência de aumento da incidência anual de trabalhadores compatíveis ocupacionais, observada de 1999-2005, manteve-se nos anos seguintes e é ainda mais acentuada, sobretudo, após a crise econômica de 2008-2009. O número de novos casos de compatíveis ocupacionais passou de 45, em 2010, para 87, em 2011, e, após a queda, para 68, em 2012, atingiu 127 e 136 novos casos, em 2013 e 2014, respectivamente (Secretaria de Previdência, Ministério da Fazenda. Tabelas - CNAE 2.0. http://www.previdencia.gov.br/dados-abertos/menu-de-apoio-estatisticas-seguranca-e-saudeocupacional-tabelas-cnae-2-0/, acessado em 17/Out/2017). Igual trajetória ascendente ocorreu com a frequência relativa (Tabela 1 ).

O período de 2010-2014 registrou o total de 463 novos casos de compatíveis ocupacionais. Esse número é mais de duas vezes os 210 casos de ocupacionais registrados de 1999-2005 e 43\% maior que o total de 323 compatíveis (ocupacional e não ocupacional) nesse mesmo período. 
Tabela 1

Novos casos de trabalhadores compatíveis ocupacionais (frequência absoluta e frequência relativa) na montadora, 2010-2014.

\begin{tabular}{lcc}
\hline Ano & Frequência absoluta & Prevalência (x 10.000) \\
\hline 2010 & 45 & 39 \\
2011 & 87 & 71 \\
2012 & 68 & 57 \\
2013 & 127 & 105 \\
2014 & 136 & 129 \\
Total & 463 & - \\
\hline
\end{tabular}

Fonte: Secretaria de Previdência, Ministério da Fazenda. Tabelas - CNAE 2.0 (http://www.previdencia.gov.br/dadosabertos/menu-de-apoio-estatisticas-seguranca-e-saude-ocupacional-tabelas-cnae-2-0/, acessado em 17/Out/2017).

O perfil dos danos à saúde dos compatíveis de etiologia relacionada ao trabalho segue inalterado: problemas psíquicos e DCNT (exceto LER) continuam praticamente excluídos desse perfil. Nas montadoras de autoveículos, é muito baixo o quantitativo/ano de benefícios auxílios-doença acidentários (B91), relativamente ao benefício previdenciário (B31), para as DCNT e os transtornos mentais e comportamentais.

As Tabelas 2 e 3 confirmam essa assertiva, mesmo após implantação, em 2007, do Nexo Técnico Epidemiológico (NTEP) para caracterização da natureza acidentaria dos benefícios por incapacidade pelo INSS. Desde sua vigência, a regulamentação do NTEP não incluiu o CNAE 2910 - montadoras de automóveis, camionetas e utilitários; para o CNAE 2920 - montadoras de caminhões e ônibus, somente para alguns grupos da 10a revisão da Classificação Interncaional de Doenças (CID-10). Entretanto, estudo 18 atualizando as bases do NTEP confirma o nexo entre o trabalho e uma série de doenças para o CNAE 2910.

O exame dos obstáculos ao retorno ao trabalho dos compatíveis pode contribuir para apreensão das características da intensificação do trabalho e suas implicações no processo saúde-doença dos trabalhadores.

\section{Obstáculos ao retorno ao trabalho do compatível}

Para o retorno ao trabalho, a empresa deve identificar um posto de trabalho compatível à atual capacidade laboral do trabalhador, conforme orientação da reabilitação profissional do INSS. Registra-se, contudo, a omissão desse órgão na efetiva reintegração do trabalhador compatível com mudanças das condições de trabalho ${ }^{17}$. A identificação do posto é realizada pelo médico do trabalho da empresa com participação do analista de recursos humanos, da chefia imediata, do próprio trabalhador e dos representantes da CIPA/CSE.

As restrições laborais (posições forçadas; limitações quanto à utilização da força física; movimentos repetitivos ou indevidos do corpo) constituem um obstáculo para o efetivo retorno ao trabalho do compatível. Alguns trabalhadores compatíveis, avaliados com elevado comprometimento da capacidade produtiva, ao serem transferidos da produção direta para atividades administrativas, expressam sentimento de inutilidade. A condição de compatível é considerada como uma "condenação":

"...você tem três, quatro comunicação de acidente de trabalho, a carteira toda carimbada. Um cara novo poderia falar, ah, eu tenho minha formação, eu vou embora. Mas, quando você chegar em outra empresa, que olhar aquele monte de carimbo, você está condenado, não vai conseguir nada".

Para esses trabalhadores, embora a estabilidade até aposentadoria contribua para permanência na empresa, esse tempo é vivenciado como uma penalidade: "Eu estou cumprindo os meus dias". Da perspectiva desses trabalhadores, a continuidade na empresa é marcada pela luta cotidiana para vencer o sofrimento imposto pelo aprisionamento ao vazio do trabalho, um tempo sem acontecimento, 
Tabela 2

Benefícios auxílios-doença previdenciários (B31) e acidentários (B91), segundo os grupos da 10ạ revisão da Classificação Internacional de Doenças (CID-10) com maiores incidências para o CNAE 2910 - montadoras de automóveis, camionetas e utilitários. Brasil, 2009-2013.

\begin{tabular}{|c|c|c|c|c|c|c|c|}
\hline CID-10 & Benefício & 2009 & 2010 & 2011 & 2012 & 2013 & Total \\
\hline \multirow[t]{2}{*}{ Doenças do sistema osteomuscular e do tecido conjuntivo (M00-M99) } & B31 & 1.184 & 1.350 & 1.498 & 1.724 & 1.824 & 7.580 \\
\hline & B91 & 746 & 735 & 724 & 682 & 750 & 3.637 \\
\hline \multirow{2}{*}{$\begin{array}{l}\text { Lesões, envenenamento e algumas outras consequências de causas } \\
\text { externas (S00-T98) }\end{array}$} & B31 & 779 & 927 & 1.008 & 963 & 1.101 & 4.778 \\
\hline & B91 & 44 & 47 & 40 & 30 & 39 & 200 \\
\hline \multirow[t]{2}{*}{ Transtornos mentais e comportamentais (F00-F99) } & B31 & 361 & 359 & 414 & 406 & 419 & 1.959 \\
\hline & B91 & 24 & 29 & 13 & 28 & 23 & 117 \\
\hline \multirow[t]{2}{*}{ Doenças do aparelho digestivo (K00-K93) } & B31 & 260 & 290 & 338 & 312 & 373 & 1.573 \\
\hline & B91 & 23 & 35 & 32 & 22 & 20 & 132 \\
\hline \multirow[t]{2}{*}{ Doenças do aparelho circulatório (100-199) } & B31 & 182 & 182 & 167 & 185 & 209 & 925 \\
\hline & B91 & 12 & 30 & 15 & 12 & 6 & 75 \\
\hline \multirow[t]{2}{*}{ Doenças do sistema nervoso (G00-G99) } & B31 & 66 & 68 & 105 & 116 & 119 & 474 \\
\hline & B91 & 32 & 31 & 44 & 45 & 39 & 191 \\
\hline
\end{tabular}

Fonte: Secretaria de Previdência, Ministério da Fazenda. Tabelas - CNAE 2.0 (http://www.previdencia.gov.br/dados-abertos/menu-de-apoio-estatisticasseguranca-e-saude-ocupacional-tabelas-cnae-2-0/, acessado em 17/Out/2017).

Tabela 3

Benefícios auxílios-doença previdenciários (B31) e acidentários (B91), segundo os grupos da 10ạ revisão da Classificação Internacional de Doenças (CID-10) com maiores incidências para o CNAE 2920 - montadoras de automóveis, camionetas e utilitários. Brasil, 2009-2013.

\begin{tabular}{|c|c|c|c|c|c|c|c|}
\hline CID-10 & Benefício & 2009 & 2010 & 2011 & 2012 & 2013 & Total \\
\hline \multirow[t]{2}{*}{ Doenças do sistema osteomuscular e do tecido conjuntivo (M00-M99) } & B31 & 423 & 377 & 492 & 587 & 546 & 2.425 \\
\hline & B91 & 169 & 135 & 86 & 108 & 151 & 649 \\
\hline Lesões, envenenamento e algumas outras consequências de causas & B31 & 328 & 356 & 363 & 368 & 370 & 1.785 \\
\hline externas (S00-T98) & B91 & 11 & 11 & 10 & 8 & 7 & 47 \\
\hline \multirow[t]{2}{*}{ Transtornos mentais e comportamentais (F00-F99) } & B31 & 107 & 144 & 158 & 135 & 149 & 693 \\
\hline & B91 & 4 & 6 & 2 & 6 & 3 & 21 \\
\hline \multirow[t]{2}{*}{ Doenças do aparelho digestivo (K00-K93) } & B31 & 115 & 106 & 140 & 150 & 128 & 639 \\
\hline & B91 & 1 & - & - & - & - & 1 \\
\hline \multirow[t]{2}{*}{ Doenças do aparelho circulatório (100-199) } & B31 & 66 & 54 & 60 & 65 & 73 & 318 \\
\hline & B91 & 6 & 5 & 4 & 2 & 5 & 22 \\
\hline \multirow[t]{2}{*}{ Doenças do sistema nervoso (G00-G99) } & B31 & 24 & 22 & 28 & 31 & 24 & 129 \\
\hline & B91 & 5 & 6 & 2 & 4 & 5 & 22 \\
\hline
\end{tabular}

Fonte: Secretaria de Previdência, Ministério da Fazenda. Acidentalidade por CNPJ (http://www.previdencia.gov.br/saude-e-seguranca-do-trabalhador/ acidentalidade-por-cnpj/, acessado em 17/Out/2017).

diante da ausência de perspectiva de recolocação e progressão profissional na montadora ou em outra empresa pela carteira "suja" com os carimbos do INSS 17.

Esse sofrimento também é comum a outros trabalhadores compatíveis que retornam para os setores de produção, mas permanecem "lá de canto":

"Ele já fez uma cirurgia na coluna e agora vai fazer outra. Está compatível (...) psicologicamente está acabado. Porque ele fica lá de canto. Não tem uma tarefa para ele fazer ali. As pessoas começam a fazer piadas, olhar feio, chamar de vagabundo". 
Outra barreira para o efetivo retorno do compatível é o prolongado tempo de afastamento do trabalho para tratamento da doença, sua continuidade ou de comorbidades desencadeadas ou agravadas.

"Ele trabalha a semana inteira normal, daí uns cinco minutos começa a chorar, fica com medo de todo mundo se tremendo todo, ai afasta, fica dois, três dias afastado e volta trabalhar normal. (...) Agora tem alguns trabalhadores que já estão afastados há um ano e pouco, porque estão com síndrome do pânico, problemas mentais, estresse".

Esses resultados são corroborados por estudo epidemiológico 19 e empírico 20: quanto maior o tempo de afastamento por doença, maior o obstáculo para o retorno ao trabalho. Especialmente os afastamentos por transtornos mentais e comportamentais, a terceira maior causa de concessão de auxílio-doença acidentário, em geral, de longa duração 19 ou sucessivos afastamentos de curta duração, como os por depressão, que prolongam o tempo fora do ambiente laboral 20.

A dificuldade de encontrar um trabalho compatível constitui um constrangimento para o trabalhador solicitar o reconhecimento das restrições laborais, ainda que tenha obtido diagnóstico em serviço médico particular: "Muitas áreas não têm [um trabalho compatível] e muitos caras acabam nem querendo ir ao ambulatório médico para registrar a doença dele para não ficar taxado de vagabundo".

Pelos depoimentos, é possível inferir que, embora bastante elevada, a quantidade de compatíveis registrada pela empresa está subestimada, um entendimento também sugerido pela atuação da CIPA/ CSE no sentido de identificar esses trabalhadores. A existência de compatíveis, sem reconhecimento legal, apresenta-se como uma situação permanente e não pontual, tanto mais com o reforço de formas de violência simbólica relacionada à gestão, como a difusão da imagem do compatível como "vagabundo", que "rouba a empresa", cujo desempenho é inferior às exigências da empresa.

Com efeito, esse contexto de trabalho contribui para o trabalhador retardar o tratamento, o que pode ampliar a gravidade dos danos à saúde, o tempo de afastamento e as restrições laborais. É o que fica evidente no relato: "Em [19]96, eu já sabia que tinha lesão na coluna. Só que eu fiquei com medo (...) só vim revelar [em 2002] quando eu não aguentava mais". Se a busca do reconhecimento da doença ocorreu apenas quando o operário não suportava mais trabalhar, significativamente, ele escolheu o momento (2002) em que havia ameaça de demissões. Quer dizer, no qual ele poderia lançar mão da prerrogativa da estabilidade. Tal interpretação é apoiada na observação do aumento de novos casos de compatíveis, especialmente ocupacionais, em 2002 (Figura 1).

Cabe assinalar que o perfil das restrições, o prolongado tempo de afastamento e/os sucessivos afastamentos por acidente ou doença geradora da redução de capacidade, bem como a dificuldade para encontrar um trabalho compatível podem ser entendidos como resultados do modo como se transforma a produção na empresa e, nesse processo, da intensificação do trabalho.

\section{Trabalhador compatível: fratura exposta da produção e da intensificação do trabalho}

Passamos a examinar as características da intensificação do trabalho, como indicamos antes, por meio dos obstáculos ao retorno e à permanência dos compatíveis no processo de produção. Mesmo porque a imensa maioria dos compatíveis retorna e desempenha suas atividades na produção direta, pressionados a trabalhar no grau de intensidade exigido pela gestão, e não segundo sua capacidade produtiva.

A identificação do posto de trabalho compatível parece minimizar ou desconsiderar as características da intensificação do trabalho 5 , como as exigências de intenso ritmo, apesar do conhecimento das limitações laborais: "Hoje eu uso duas próteses. (...) O médico não autoriza eu trabalhar mais na máquina. Por causa dos movimentos e do peso. Fiquei com uma restrição muito grande”. A reinserção desse operário foi efetivada em um posto imediatamente antes da linha de montagem, sua atividade consistia na aferição final da qualidade das peças e enviá-las à linha, um posto considerado "trabalho em serviços leves". Contudo, narra o operário, "o ritmo é um ritmo a todo vapor (...) a gente trabalha no ritmo da linha. Se a linha fizer dez peças, eu vou fazer dez, se ela fizer cem, eu vou fazer cem”.

Esse caso expressa obstáculos para o retorno e a permanência dos compatíveis relacionados ao processo de intensificação do trabalho produzido ou acentuado nas sucessivas transformações produtivas na montadora desde o início dos anos 1990. Segundo as falas, as mudanças na fábrica extinguiram uma série de postos de trabalho, supostamente de menor exigência, até então destinados aos compatíveis, como o posto descrito acima para aferir a qualidade das peças antes da linha, extinto em 2012. 
$\mathrm{Na}$ linha de montagem, a inovação de produto e processo com frequentes mudanças nos modelos de caminhão (leve, médio, pesado) recrudescem a intensificação do ritmo com reforço do trabalho repetitivo e redução dos micro-descansos entre as operações. Os compatíveis originários da linha são transferidos geralmente para atividades de logística e de pré-montagem, duas operações elegíveis, pela empresa, para terceirização. A exclusão dos compatíveis da linha é um indicador do reforço da intensificação do trabalho na geração dos danos à saúde e de sua maior gravidade: "O cara não consegue mais erguer um quilo na mão. O setor fala para ele; oh, você precisa buscar um setor aí para trabalhar".

$\mathrm{Na}$ usinagem, as mudanças introduzem talhas elétricas e pneumáticas para movimentação de peças, substituem as antigas máquinas por novas com reforço da organização da produção em células e rodízio dos postos de trabalho entre os operários no grupo. Nos setores com maior frequência absoluta de compatíveis, majoritariamente originários e mantidos nesses setores, essas mudanças são acompanhadas da terceirização, ampliada após a crise econômica de 2008-2009: "A peça pesada ruim de trabalhar está sendo terceirizada". Ou seja, a terceirização, ora em expansão, enquanto instrumento de gestão para redução de custos com a força de trabalho e externalização dos conflitos trabalhistas e previdenciários e os relativos à saúde dos trabalhadores, acentua a tendência de exclusão dos compatíveis.

A direção das mudanças tecnológicas, organizacionais e de gestão resulta no maior adensamento do trabalho pelo acréscimo de mais tarefas para o trabalhador individual e o grupo, outra característica da intensificação. Nesse sentido, a percepção operária das mudanças como processo que intensifica o ritmo inclui as chamadas "melhorias ergonômicas" que, em tese, facilitam o trabalho: "desde que eu estou aqui eles [gerência] sempre tentam fazer melhorias em equipamentos, supostamente deixar o seu trabalho mais fácil, mas acabam que tirando uma responsabilidade e te colocam mais duas". Dessa forma, além de reforçar a intensificação, colocam obstáculos à permanência dos compatíveis.

O prolongamento da jornada de trabalho é outra característica do processo de produção, que alcança todos os trabalhadores, inclusive os compatíveis. Constitui uma exigência de disponibilidade para trabalhar-se mais horas, especialmente por meio da jornada adicional, realizada aos sábados, domingos ou feriados, bem numerosa em momentos de alta produção: em 2010 e 2011, ocorreram 25 e 27, respectivamente. Para os operários, essa jornada aumenta seu desgaste, pois prolonga a sequência de dias de trabalho ao excluir o descanso semanal e porque, nesses dias, trabalha-se bem mais do que nos demais.

O banco de horas também prolonga a jornada diária e mantém a jornada semanal acima das quarenta horas, como prevista no acordo coletivo em 1999. Desde então, essa jornada prolongada pelo banco de horas constitui a jornada "habitual" na empresa. O intenso ritmo é citado como motivação para utilização da folga individual pelo banco de horas, muitas vezes, para o operário descansar. Mas, ao mesmo tempo, a folga provoca sobrecarga nos demais trabalhadores do grupo para alcançar as metas de produção.

A gestão das metas de produção e, nessas condições, o trabalho em grupo também foram apontados como obstáculos para a permanência do compatível. Apesar da redução da capacidade laboral do compatível ser formalmente reconhecida como plena à sua condição, o sistema de gestão da empresa computa as metas de produção pela produtividade do trabalhador sem restrição médica. Segundo relatos, o sistema de metas insere o "estresse" no processo de produção, especialmente por sua vinculação ao pagamento da participação nos lucros ou resultados (PLR) 5. As exigências para trabalhar mais intensamente recaem também nos compatíveis. Nesse contexto, o grupo pode constituir-se em fonte de estresse:

"Ele [compatível] tem restrição, mas, para empresa, isso não interessa não. O grupo vai ter que assumir aquela produção. Ele é um número e isso aumenta em tantas peças no final. Talvez isso seja o que criou essa discriminação com os compativeis".

A reflexão operária identifica a intensificação do trabalho, efetivada pelas práticas de gestão por metas e avaliação por performance, ao mesmo tempo em que identifica o efeito delas nos laços solidários e coletivos entre os trabalhadores, pois tende a acirrar a competitividade na direção da exclusão do compatível do grupo.

Gestão por metas e a avaliação por performance são dois instrumentos da gestão por estresse 1,5. $\mathrm{O}$ estresse, como lógica gerencial, estrutura e orienta as práticas implicadas no desempenho do trabalhador com ou sem restrição laboral. No chão da fábrica, um dos efeitos das práticas de gestão 
por estresse é a representação do compatível como "baixa performance", situação que constrange os trabalhadores a ocultar problemas e danos à sua saúde, em razão de ameaçar sua progressão salarial e expectativa de ascensão profissional. Um contexto de trabalho marcado por conflitos:

“...muitos acabam brigando com o chefe: ah, o meu chefe não ajudou pra me promover, então eu quero sair da seção. Alguns já têm problema de saúde, aí aproveita para ir ao ambulatório registrar e ficar compatível pra tudo justificar: sou compativel e não trabalho mais. E muitos acabam ficando frustrados e adoecendo".

A perda da perspectiva da ascensão profissional na montadora e o registro da condição de compatível expressam um distanciamento da racionalidade e da "ideologia da performance" em que adoecer é entendido como fraqueza 21 (p. 1151). Quer dizer, a busca pelo reconhecimento da doença pode ser um recurso para escapar das pressões gerenciais, até então suportadas pelo trabalhador. Para isso, ressaltamos a importância da estabilidade do compatível ao possibilitar maior proteção do trabalhador para lançar mão da recusa às exigências de metas crescentes e jornadas adicionais.

A estabilidade, conquista da luta sindical para proteção do compatível, é reafirmada nas formas de solidariedade operária no cotidiano da fábrica, contrariamente às pressões gerenciais por mais produtividade, como sugere o relato: "tem compativel que todo mundo trata ele como: não, esse aí é dos nossos. Tem problema de coluna porque ele ficou vinte anos trabalhando nessa talha. Hein, companheiro, deixa isso com a gente que você já fez o que tinha que fazer". Essas formas de solidariedade possibilitam ultrapassar a segmentação entre os trabalhadores, por exemplo, com ou sem restrição médica, e situar os problemas de saúde em relação às pressões da produção, conferindo-lhes um sentido coletivo.

No entanto, a condição de compatível contraria o perfil de trabalhador valorizado pela gestão por estresse. Por conseguinte, pode acarretar em transferências, com a exclusão do compatível do convívio com os colegas do grupo e do setor, o risco de passar a "rodar a fábrica toda" em sucessivos "empréstimos" para outras áreas até, no limite, a demissão.

Por meio do "programa de demissão voluntária" (PDV), acontecem as demissões em massa na empresa, especialmente em contexto de crise econômica como em 2009. Na ocasião, foram demitidos 1.600 trabalhadores, principalmente aposentados e os avaliados como "baixa performance", inclusive compatíveis. O "convite" apresentado ao jovem operário ilustra a natureza de exclusão seletiva dessa forma de demissão:

"Eu tenho tendinite crônica no tendão de Aquiles (...) ficava muito tempo em pé, só sentava na hora da refeição. Fiquei dois anos assim. Um ano foi de contrato e o outro já era funcionário da empresa. (...) Na época da crise, eu fui convidado a pegar o pacote [PDV], estava com 23 anos".

Em outros termos, a demissão por PDV sanciona a exclusão dos compatíveis da montadora, enquanto o processo de intensificação do trabalho seleciona esses trabalhadores 22.

A partir de 1999, a efetivação na empresa acontece após um período de contrato por prazo determinado, geralmente de um ano, utilizado como processo de seleção dos trabalhadores. Essa modalidade de contratação participa da gestão por estresse com implicações para todo o coletivo operário: cada admissão de uma nova turma parece recrudescer as exigências gerenciais e a competição entre os trabalhadores pelo alcance das metas:

“...em vez de cem, igual aos outros que já são mais antigos, quer fazer cento e vinte peças para mostrar que ele é bom. Muitos desses trabalhadores [de contrato por prazo determinado] acabam se acidentando, adoecendo, porque com a talha demora trinta segundos para ele por uma peça, com a mão é cinco. Então ele vai com a mão, aí começa".

Quer dizer, o desgaste produzido pela intensificação do trabalho em pouco tempo pode degradar a saúde dos trabalhadores, como é o caso dos jovens operários:

"Eu conheço várias colegas novas que têm problema no ombro ou têm problema na coluna. E também muita gente desgastada emocionalmente falando. Tem colega afastado e não sei quando volta porque, de repente, a cabeça pirou. O médico já falou que é crônico. Não sei se ele retorna. Eu acredito que essa rotina também estressante pode ter acarretado".

Os relatos também chamam a atenção para as frequentes queixas entre os jovens operários: " $A$ molecada nova reclamando que está com dor nas costas, tomando Dorflex direto". As exigências gerenciais para trabalhar mais horas e mais intensamente também incluem mitigar ou silenciar os sintomas de dor.

As queixas de dor e os casos de compatíveis entre jovens operários apoiam a tendência de continuidade e agravamento dos danos à saúde dos trabalhadores apontada na Tabela 1. 
A intensificação do trabalho é um processo marcado por contradições, no qual se insere a resistência operária. Importa observar a predominância das formas moleculares de resistência às práticas de intensificação. $\mathrm{O}$ absenteísmo, especialmente nas jornadas adicionais, e o distanciamento do trabalhador em relação à racionalidade gerencial, expresso no reconhecimento da doença, são duas dessas formas que contêm a crítica, do ponto de vista das condições mais imediatas dos operários. No entanto, seus sentidos em termos da ação coletiva permanecem difusos, tanto mais quando essas experiências são eclipsadas pela ação sindical 5 .

A direção do Sindicato dos Metalúrgicos do $\mathrm{ABC}$, frente aos conflitos entre empresas e trabalhadores, desde a participação sindical na Câmara Setorial da Indústria Automotiva (1992-1993), assumiu uma posição comumente chamada de "ganha-ganha" 5 . Isso se traduz na busca do sindicato em compatibilizar compromissos para viabilizar competitividade e produtividade das empresas com o emprego e a saúde dos trabalhadores.

Na montadora, a participação sindical na cogestão da produção e da força de trabalho significou aprovação de acordos coletivos, tais como: PLR, banco de horas, jornadas adicionais, contrato por prazo determinado e terceirização.

Esses instrumentos incorporados nas práticas de gestão da empresa marcam o atual processo de intensificação do trabalho implicando, de um lado, a eliminação de uma série de postos de trabalho em toda a fábrica, ainda mais acentuada com a expansão da terceirização; e, de outro, o modo como se produz o desgaste laboral expresso no crescimento do número de compatíveis. Portanto, a intensificação do trabalho questiona a posição sindical de compatibilizar aumento da produtividade com emprego e saúde. O questionamento também está presente no coletivo de trabalhadores, ainda que difuso, como apontamos antes nas formas moleculares de resistência.

A cogestão sindical não impede o conflito no chão da fábrica, como os relativos à saúde dos trabalhadores, inclusive por iniciativa de operários, cipeiros e ativistas sindicais de base. No entanto, a direção sindical altera a compreensão acerca desses conflitos: deixa de questionar mais amplamente a determinação das doenças e dos agravos à saúde pela intensificação do trabalho para direcionar sua ação basicamente para tratar dos "riscos" que podem ser negociados pontualmente e passíveis de intervenção específica. $\mathrm{O}$ foco recai em propor medidas de proteção ergonômica relativas ao posto de trabalho: "Oh, precisa de uma talha, precisa automatizar a esteira, para adaptar isso ao homem". E, nesse sentido, a ação sindical estabelece pontos de contato com a lógica gerencial, pois, como indicamos, tais medidas estão incorporadas nas transformações na produção que reforçam a intensificação do trabalho.

Igualmente, a ação sindical na prevenção limita seu olhar basicamente ao posto de trabalho: " $A$ máquina que acidentou ele, a máquina que ele está com tendinite. Tem que agir naquela máquina para que o outro que for trabalhar nela não fique doente". O posto de trabalho aparece como unidade de análise e sem estabelecer as relações com o conjunto do processo de produção na montadora em sua dinâmica global 13 .

O posto de trabalho como unidade de análise, com efeito, focaliza "riscos" mais imediatos à geração de agravos e doenças bem específicos, em geral, redutível ao atual perfil dos compatíveis ocupacionais.

Quer dizer, a noção de posto de trabalho é parcial. Sua natureza parcial obstrui o avanço do conhecimento e da intervenção em direção à multiplicidade dos problemas de saúde e de sua determinação pela intensificação do trabalho, especialmente pelas características da gestão e organização do trabalho. Por conseguinte, são excluídas da pauta sindical para o enfrentamento pelo coletivo de trabalhadores.

Essa postura não é exclusiva a esse sindicato. Em debate sobre o sofrimento psíquico na França, Lallement et al. 23 criticam a adoção de discurso tecnicista pelos sindicatos sustentando, em contrapartida, a necessidade de ação política em defesa da saúde no trabalho. Sabe-se que a política sindical no enfrentamento à intensificação pode ser decisiva 2. A análise da ação sindical na Austrália, por exemplo, mostrou-se mais efetiva nos sindicatos que não adotaram a estratégia "produtivista" no pacto para o enfrentamento da competitividade global 24.

Além disso, para os sindicatos, é fundamental conhecer e intervir sobre as tecnologias de gestão, não apenas porque não são baseadas em princípios humanísticos, mas porque não são necessariamente 
fundadas em bases empíricas, por vezes, são contraprodutivas segundo a própria racionalidade gerencial e, sobretudo, podem ser vetores de violência 25 .

\section{Considerações finais}

Neste estudo, o entendimento do adoecimento do compatível como um sinal permitiu refletir sobre os problemas de saúde do coletivo operário e sua determinação a partir da experiência dos trabalhadores.

O trabalhador compatível indica uma fratura exposta pelo processo de produção, provocado pela intensificação do trabalho, caracterizada na gestão por estresse, ritmo intenso, adensamento do trabalho e prolongamento da jornada.

Essas características apontadas pelos trabalhadores como responsáveis pelos acidentes de trabalho e LER também estão associadas aos transtornos psicoafetivos e às DCNT; morbidades praticamente excluídas do perfil do compatível ocupacional, bem como do benefício auxílio-doença acidentário concedido aos operários das montadoras. A relação entre intensificação do trabalho e doenças crônicas merece a atenção das pesquisas e das políticas de saúde.

Além disso, o reconhecimento dos problemas de saúde-doença relacionados ao trabalho pela empresa e pela previdência constitui um processo marcado por conflitos no processo de produção e nas relações entre ciência/técnica e política. Sua determinação histórica e social também implica a capacidade da ação sindical/coletiva no sentido de situar os problemas de saúde e proteger os trabalhadores.

Todavia, a recente extinção do Ministério da Previdência Social, com transferência do INSS para o Ministério do Desenvolvimento Social e do Conselho Nacional de Previdência, responsável por deliberar sobre política e gestão previdenciária, para a Fazenda, cristaliza, nas estruturas administrativas, a racionalidade fiscal no enquadramento dos benefícios, confrontando e colocando, em risco, direitos sociais, entre eles, os dos compatíveis.

É, portanto, fundamental avançar os conhecimentos acerca da intensificação do trabalho e saúde, inclusive em relação à política de proteção social, com incorporação da experiência dos trabalhadores.

\section{Colaboradores}

J. A. Pina participou da concepção, planejamento, análise e interpretação dos dados, redação do artigo e na aprovação da versão final. E. N. Stotz colaborou na concepção, planejamento, revisão crítica do conteúdo do artigo e na aprovação da versão final. J. M. Jackson Filho colaborou na concepção, na revisão crítica do conteúdo do artigo e na aprovação da versão final.

\section{Agradecimentos}

Agradecemos ao apoio da Escola Nacional de Saúde Pública Sergio Arouca, Fundação Oswaldo Cruz. 


\section{Referências}

1. Parker M, Slaughetr P. Unions and management by stress. In: Babson S, editor. Lean work: empowerment and exploitation in the global auto industry. Detroit: Wayne State University; 1995. p. 41-53.

2. Askenazy P, Cartorn D, Conninck F, Gollac M, editors. Organisation et intensité du travail. Toulouse: Octarès; 2006.

3. Findlay P, Thompson P. Contemporary work: its meanings and demands. J Ind Relat 2017; 59:122-38.

4. Dal Rosso S. Mais trabalho: a intensificação do labor na sociedade contemporânea. São Paulo: Boitempo Editorial; 2008.

5. Pina JA, Stotz EN. Intensificação do trabalho e saúde dos trabalhadores: um estudo na Mercedes Benz do Brasil, São Bernardo do Campo, São Paulo. Saúde Soc 2015; 24:826-40.

6. Marx K. O capital: crítica da economia política. São Paulo: Editora Abril Cultural; 1984.

7. Landisbergis PA, Cahill J, Schnall P. The impact of lean production and related new systems of work organization on worker health. J Occup Health Psychol 1999; 4:108-30.

8. Lacaz FAC. Qualidade de vida no trabalho e saúde/doença. Ciênc Saúde Coletiva 2000; 5:151-61.

9. Fairris D, Brenner M. Workplace transformation and the rise in cumulative trauma disorders: is there a connection? J Labor Res 2001; 22:15-28.

10. Felstead A, Gallie D, Green F, Inanc H. Work intensification in Britain: first findings from the Skills and Employment Survey 2012. London: Centre for Learning and Life Chances in Knowledge Economies and Societies, Institute of Education; 2013.

11. Lima MEA, Batista MA. As novas exigências de qualificação e a saúde no setor automotivo. Psicologia em Revista 2003; 9:159-64.

12. Berlinguer G. A doença. São Paulo: Editora Hucitec; 1988.

13. Laurell AC, Noriega M. Processo de produção e saúde: trabalho e desgaste operário. São Paulo: Editora Hucitec; 1989.

14. Bourdieu P. A miséria do mundo. Petrópolis: Editora Vozes; 1999.

15. Ramalho JR, Santos R. Huw Beynon: marxismo e sociologia. Sociologia \& Antropologia 2016; 6:13-29.
16. Viegas LRT, Almeida MMC. Perfil epidemiológico dos casos de LER/DORT entre trabalhadores da indústria no Brasil no período de 2007 a 2013. Rev Bras Saúde Ocup 2016; 41:e22.

17. Maeno M, Wünsch Filho V. Reinserção no mercado de trabalho de ex-trabalhadores com LER/DORT de uma empresa eletrônica na região metropolitana de São Paulo. Rev Bras Saúde Ocup 2010; 35:53-63.

18. Oliveira PRA. Nexo Técnico Epidemiológico Previdenciário - NTEP e Fator Acidentário de Prevenção - FAP: um novo olhar sobre a saúde do trabalhador. 2a Ed. São Paulo: Editora LTr; 2010.

19. Silva Junior JS, Fischer FM. Adoecimento mental incapacitante: benefícios previdenciários no Brasil entre 2008-2011. Rev Saúde Pública 2014; 48:186-90.

20. Cavalheiro G, Tolfo SR. Trabalho e depressão: um estudo com profissionais afastados do ambiente laboral. Psico USF 2011; 16:241-9.

21. Seligmann-Silva E. Psicopatologia e saúde mental no trabalho. In: Mendes R, organizador. Patologia do trabalho. São Paulo: Editora Atheneu; 2003. p. 1141-82.

22. Glina DMR, Rocha LE, Batista ML, Mendonça MGV. Saúde mental e trabalho: uma reflexão sobre o nexo com o trabalho e o diagnóstico, com base na prática. Cad Saúde Pública 2001; 17:607-16.

23. Lallement M, Marry C, Loriol M, Molinier P, Gollac M, Marichalar P, et al. Les maux du travail: dégradation, recomposition ou illusion? Sociol Trav 2011; 53:3-36.

24. Buchanan B, Briggs C, Considine G. Les syndicats et l'intensification du travail: aperçus des secteurs australiens du métal, de l'ingénierie et des soins infirmiers. In: Askenazy P, Cartorn D, Conninck F, Gollac M, editors. Organisation et intensité du travail. Toulouse: Octarès; 2006. p. 399-408.

25. Taylor P. Performance management and the new workplace tyranny: a report for the Scottish Trade Union Congress. Glasgow: University of Strathclyde; 2013. 


\begin{abstract}
Today's intensification of labor is part of the industrial transformations under way in Brazil since the 1990s, involving changes in the social production of auto workers' strain and epidemiological profile. Accident- and disease-related absenteeism is an important indicator of auto workers' strain, with relevance to the health field. The study aims to analyze the intensification of labor and its health implications from the perspective of the health-disease process, based on workers' perceptions at an automobile assembly plant in the ABC Industrial Belt of São Paulo. Workers were asked about the obstacles to returning to work following work-related accidents or diseases (commonly referred to as "compatible" workers). We conducted six visits to the plant and 20 interviews with assembly line workers. Data were collected from March 2010 to November 2014. The results depict the social figure of the "compatible" worker, a "compound fracture" in the production process, expressed as the intensification of labor, characterized by an intense work pace, denser work, extended workdays, and heavy stress, while simultaneously pointing to a trend toward laying off "compatible" workers. The study contributes to the search for knowledge on the intensification of labor and its health implications. We hope to have produced backing for further research on determination of the health-disease process, based on the incorporation of workers' experience.
\end{abstract}

Workload; Social Security; Occupational Health

\section{Resumen}

El actual proceso de intensificación del trabajo se inserta en el contexto de las transformaciones productivas en Brasil, acaecidas a partir de los años noventa, y que acarrearon cambios en la producción social, en el desgaste del obrero y el perfil epidemiológico de los trabajadores. La incapacidad para el trabajo por accidente y enfermedad es un importante indicador del desgaste del trabajador, siendo un área de interés para la salud. El estudio tuvo como objetivo analizar el proceso de intensificación del trabajo y su repercusión en la salud, desde la perspectiva del proceso salud-enfermedad, a partir de la percepción de los trabajadores de una ensambladora automovilística de la Región del ABC, en São Paulo. Realizamos encuestas, a obreros con restricciones laborales por accidente o enfermedades, denominados comúnmente "compatibles", sobre sus obstáculos para el retorno al trabajo. Realizamos seis visitas a la fábrica $y$ veinte entrevistas a obreros del área de producción. Los datos fueron recogidos entre marzo de 2010 y noviembre de 2014. Los resultados revelan, en la figura social del "compatible", una fractura expuesta por el proceso de producción, expresada en las prácticas de intensificación del trabajo, caracterizada por el ritmo intenso, densificación del trabajo, prolongación de la jornada y gestión del estrés; al mismo tiempo, apuntan hacia la tendencia de exclusión del trabajador "compatible" de la empresa. La investigación contribuye al avance en la búsqueda del conocimiento sobre la intensificación del trabajo y sus efectos sobre la salud. Esperamos servir de apoyo de nuevas investigaciones, desde la perspectiva del proceso salud-enfermedad, con la incorporación de la experiencia de los trabajadores.

Carga de Trabajo; Seguridad Social;

Salud Laboral
Recebido em 04/Jul/2017

Versão fianl reapresentada em 07/Dez/2017

Aprovado em 26/Jan/2018 